\title{
Combustability of building products versus fire safety
}

\author{
J. FANGRAT* \\ Instytut Techniki Budowlanej, 1 Filtrowa St., 00-611 Warszawa
}

\begin{abstract}
The combustion process is described and analysed based on the experimental results in the context of building fire safety. Data are obtained by means of five standard methods: ISO 5657 ignitability test, ISO 5657 cone calorimeter, ISO 9705 room corner test, EN ISO 1716 small calorimeter, and EN ISO 1182 small furnace. Various categories of building products were tested: cellulose based products (particle boards, plywoods), solid wood, floor coverings, concrete, ceramics, insulations (thermal and/or acoustic), boards (wall/ceiling), mortars, adhesives, and thin coatings. The studied products exhibited very different fire properties from non-combustible to easily combustible. In order to more effectively differentiate non-combustibles and combustibles within building products, the modified heat of combustion was calculated using all test results according to EN ISO 1716 and EN ISO 1182. The revision of criteria for Euro class A1 and A2 is proposed to obtain more realistic reaction-to-fire evaluation. In conclusion, it is advised to use single limit for heat of combustion for A1 and A2 Euro class. The proposed approach for modified heat of combustion is a convenient tool for the fast and cost-effective initial test method for non-combustibility evaluation and seems to be the proper method for distinguishing between non-combustibles and combustibles within building products. It is a better reflection of the real physical process of combustion than the current one. The third A1 criterion is questionable, regarding time to auto-ignition in EN ISO 1182 cylindrical furnace. The measurement for gross heat of combustion by EN ISO 1716 method is proposed for all Euro classes of building products with different limit values.
\end{abstract}

Key words: building performance, building fire safety, building products, fire properties, Euroclass.

\section{Introduction}

Fires constitute a serious economic and social problem. Fire losses make up approx. $1 \%$ of the gross domestic product of each European country. In Poland, this level is not very different from the European average. Annually, our country faces nearly 35,000 building fires (mostly residential buildings) and this number has not fallen in recent years. Over the last few years, the number of fatalities in building fires has decreased from 605 in 2005 to 517 in 2013 . At the same time, the number of wounded and injured in fires $[1,2]$ has increased.

The explanation of how fires are initiated and spread across buildings is crucial for the fire safety of buildings. Certain part of building products tend to sustain combustion and generate heat in a fire, when the rest of them is not involved. This behaviour is described mainly as the result of the chemical composition, particularly the organic content [3-10]. Also, the internal structure and the condition of surface exposed to the ignition source have an influence on the fire characteristic of the building product due to the influence on the heat transfer in the reaction zone. Products tending to be involved in combustion are included to combustibles, while others, are defined as non-combustible. The lack of involvement to fire does not automatically mean preserving mechanical and chemical properties of the product such as: strength, appearance of defects and cracks, dripping and falling residue, due to, firstly, water evaporation and then gasification. Moreover, toxic or harmful

*e-mail: j.fangrat@itb.pl substances might be present in the non-combustible products of combustion. Even non-combustible (steel, concrete) loadbearing construction elements may lose fire resistance, which could cause hazard for the evacuation of habitants and firemen action.

The process of fire is so complex that it is impossible to express quantitatively all the variables necessary to design or estimate functional properties with an accuracy that will make their application credible. Products of combustion in a fire are chemical compounds and thermal energy emitted in an uncontrollable way. The formation of these combustion products has a negative impact on structures, people and the environment. Therefore, it is necessary to analyse the issue regarding fire safety of buildings in connection with the combustion processes that occur during a fire, involving the construction products containing combustible organics - it is becoming more and more common, as a result of increasing environmental requirements.

Environmental aspects give rise to new issues related to the fire safety of buildings and their significance will grow in the future. In light of the following, it is particularly important to formulate the appropriate requirements for construction products in a precise and relatively simple way, in order to differentiate the non-combustible and combustible products in various fire initiation conditions. It becomes necessary to develop/ modify the requirements of fire safety to implement modern environmentally-friendly products in the construction industry.

The purpose of the study was to define the properties of combustible construction products, which are essential for fire development, and thus for the fire safety of buildings. The main 
objective for this particular article is to present my original concept of modified heat of combustion in a wider context of building fire safety. The concept itself was already presented in a strictly focussed publication [11]. Having in mind the interdisciplinary nature of the community of potential readers (examples in $[12,13])$, I have decided to add a short general description of the most important processes and phenomena accompanying fire development in building, illustrating it by my own results, just to show the heat of combustion in a wider context, because it is not the only significant value for the combustion in fire. Each of these subjects might be presented as a separate book or at least a chapter in the book. There are plenty of important publications on each of these topics. It is not my objective to give a state-of-art or to present them in details in such a short piece of work neither to make a complete list of references. The main listed references are good source of information for further studies of particular problem.

\section{The specific nature of building compartment fire}

Knowledge of combustion enables the identification of processes responsible for the supply of fuels (made from combustible material/product) and release of thermal energy. On the basis of the theoretical and experimental analysis of heat transfer from flame to unburnt fuel, researchers have formulated dependencies which affect the propagation of flame and development of fire within the building, particularly inside a room, in which there are certain conditions, such as in an enclosure separated by partitions. Numerous studies conducted in this scope have allowed researchers to understand the nature of this phenomenon and associate it with the process of ignition in the gaseous phase. Propagation of flame (fire) depends primarily on the scale and formation of air streams produced in the combustion zone and its vicinity [3-10]. It became crucial to understand the complex air exchange, completeness of the combustion process and release of thermal decomposition and combustion products that generate smoke. The concept of fire in a room is aimed at describing a fire which occurs in a room or a different separated space with the cubic volume of approx. $100 \mathrm{~m}^{3}$.

Fire development in large or very large spaces with a volume of above $1000 \mathrm{~m}^{3}$ depends primarily on the geometry of this space $[4,14,15,17,18]$ and should be analysed individually for each case, as it cannot be subject to generalisation.

The testing of fire development on a natural scale, in a standardised room with a relatively small cubic volume is performed to determine the fire properties of the so-called surface products, defined as "a part of the building which constitutes an exposed surface of internal wall and/or ceilings, e.g. panels, tiles, boards, wallpapers, sprayed or painted coverings" [18].

2.1. Fire initiation - ignition. Susceptibility of a product to ignition is referred to as ignitability [19]. This property of a product, characterised most frequently by the time to ignition, is closely related to the conditions in which the ignition occurs, but the external heat flux is of crucial importance here $[4,5$,

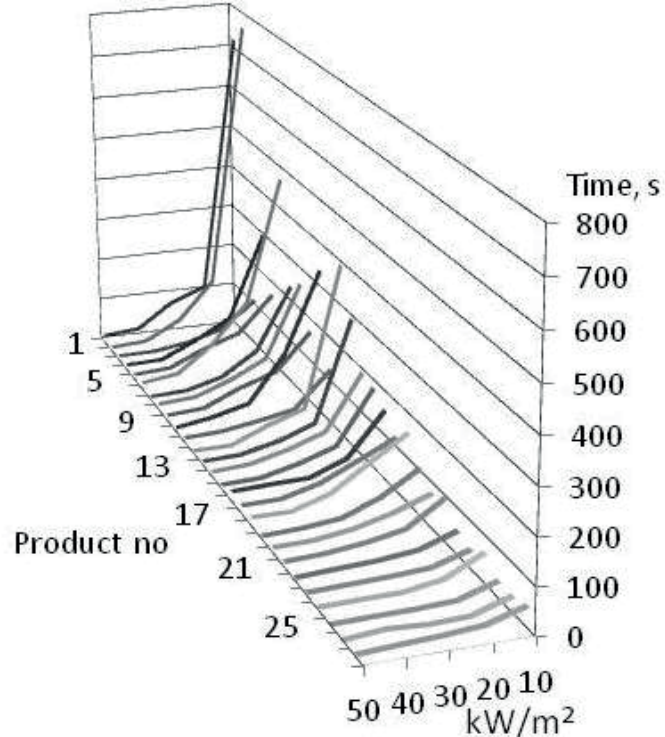

Fig. 1. Time to ignition at different external heat flux; based on [21]

$7,20]$. The time to ignition decreases as the stream of external heat flux increases. This is clearly confirmed by the results of the tests [21] performed on 27 samples from three groups: wood-based materials (Nos 1-15), solid wood (Nos 16-21) and floor coverings (Nos 22-27). The tests were conducted for five ranges of external heat flux: 10, 20, 30, 40 and $50 \mathrm{~kW} / \mathrm{m}^{2}$. Time of ignition measured for all the tested products depended on the value of external heat flux and decreased as the flux increased (Fig. 1). This dependency was the least evident in the case of floor coverings, which demonstrated the shortest time to ignition in all the ranges of external heat flux. The studies on time to ignition were complemented by tests of surface ignition temperatures conducted according to the original concept in a cone calorimeter [22, 23]. They involved the measurements of time to flaming ignition for horizontal square samples with an edge length of $10 \mathrm{~cm}$. The samples were subjected to various external heat flux levels $\left(\mathrm{kW} / \mathrm{m}^{2}\right)$ (Table 1).

Table 1

Experimentally obtained time to ignition in gas phase $\left(\mathrm{t}_{\mathrm{ig}}\right)$ and solid phase $\left(t_{i s}\right)$ for horizontal samples in the cone calorimeter [23]

\begin{tabular}{|l|c|c|c|c|c|c|}
\hline \multirow{2}{*}{ No } & \multicolumn{3}{|c|}{$\mathrm{t}_{\mathrm{ig}}(\mathrm{s})$} & \multicolumn{3}{c|}{$\mathrm{t}_{\mathrm{is}}(\mathrm{s})$} \\
\cline { 2 - 7 } & 25 & 33 & 50 & 25 & 33 & 50 \\
\cline { 2 - 7 } & \multicolumn{3}{|c|}{$\mathrm{kW} / \mathrm{m}^{2}$} & \multicolumn{3}{c|}{$\mathrm{kW} / \mathrm{m}^{2}$} \\
\hline 1. Plywood 1 & 268.0 & 79.0 & 33.3 & 263.5 & 75.1 & 29.5 \\
\hline 2. Plywood 2 & 160.3 & 63.0 & 28.1 & 155.8 & 78.0 & 24.4 \\
\hline 3. Plywood 3 & 272.8 & 48.1 & 33.3 & 269.1 & 43.4 & 28.5 \\
\hline 4. Plywood 4 & 158.2 & 81.4 & 28.2 & 153.7 & 77.1 & 23.8 \\
\hline 5. Plywood 5 & 263.8 & 54.7 & 21.6 & 259.1 & 51.0 & 11.4 \\
\hline 6. Particle board & 162.9 & 99.9 & 41.8 & 157.8 & 95.2 & 37.5 \\
\hline
\end{tabular}


Additionally an analysis of surface ignition temperature was conducted using two calculation methods described in the literature, i.e. [24] (method A in Fig. 2) and [25] (method B in Fig. 2), and in the paper [23]. Furthermore, for all the products listed in Table 1, thermo-gravimetric (TG) and derivative thermo-gravimetric (DTG) analyses were performed with the heating rate of $5 \mathrm{~K} / \mathrm{min}$ and an air flow of $100 \mathrm{ml} / \mathrm{min}$ (method C in Fig. 2). The most consistent results, with the average temperature from K-type thermocouple measurements (method D in Fig. 2), were obtained in TG, DTG analysis (method C).

\section{Surface ignition temperature, $\mathrm{K}$}

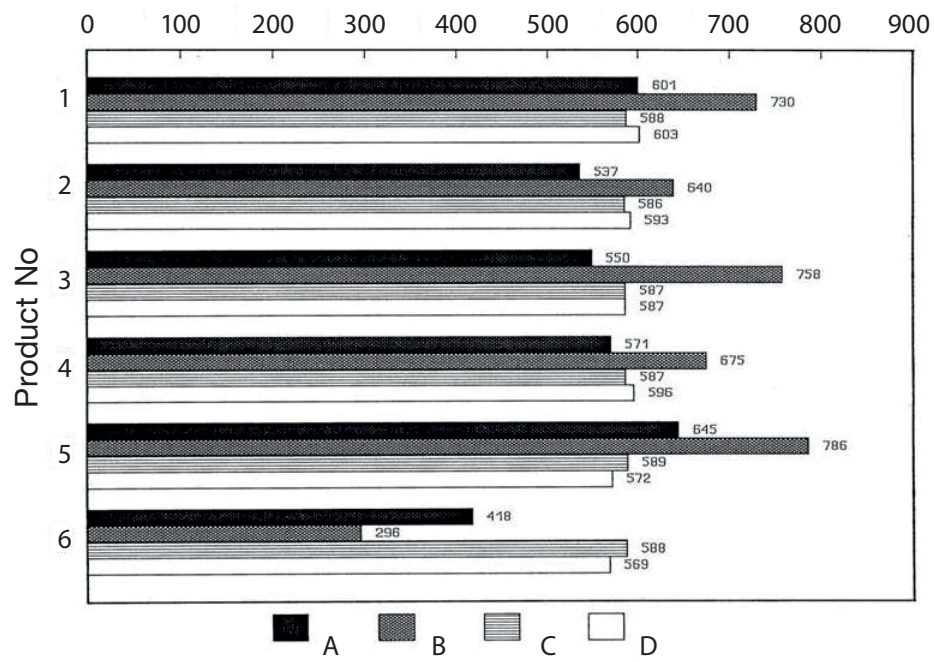

Fig. 2. Surface ignition temperature of cellulose products determined by four methods [23]: A - theoretical acc. to [24], B - theoretical acc. to [25], C - thermo gravimetric analysis of TG, DTG at the heating rate of $5^{\circ} \mathrm{C} / \mathrm{min}$ and air flow of $100 \mathrm{ml} / \mathrm{min}, \mathrm{D}$ - measurement with the K-type thermocouple [23]; numbering of the products as per Table 1

The observed differences in temperatures are within the range 0 to 17 . Both theoretical methods ( $\mathrm{A}$ and $\mathrm{B}$ ) did not give reliable results for the particle board (No 6 in Table 1). Furthermore, the conducted experiments [23] indicate that surface temperature at ignition depends mainly on the product properties then also on test conditions, such as configuration of the sample or the level of external heat flux. There is evidence which allows to conclude that various ignition mechanisms are found for both sample configurations: for the horizontal one, it is solid phase ignition, for the vertical one - gas phase ignition. This would require further studies to elucidate this matter. Based on the conducted tests and the analysis of surface ignition temperature of wood-based products, it must be stated that this value, often referred to in the literature, especially in connection with fire-related process modelling, is rather deceptive, hard to measure or to determine theoretically. The methods used commonly for its estimation in modelling may entail large errors. The results obtained in such a manner should be treated very carefully and qualitative rather than quantitative interpretation should be applied. It is also necessary to verify experimentally the calculation results obtained on this basis.

The values measured with a cone calorimeter for construction products describe the combustion process of these products very well. There may be interrelationships between these values. For example, one may observe a qualitative correlation of the effective heat of combustion (EHC, Fig. 3A) and the light extinction coefficient (LEC, Fig. 3B). For LEC, the peaks on both diagrams overlap with a certain time delay (approx. 50 sec.), resulting from the distance of the place of its measurement [26]. Light extinction can be used indirectly to show the smoke production rate of the product - an important feature for the visibility of escape routes in a building and at the same time, the safety of the people in the building during a fire. The

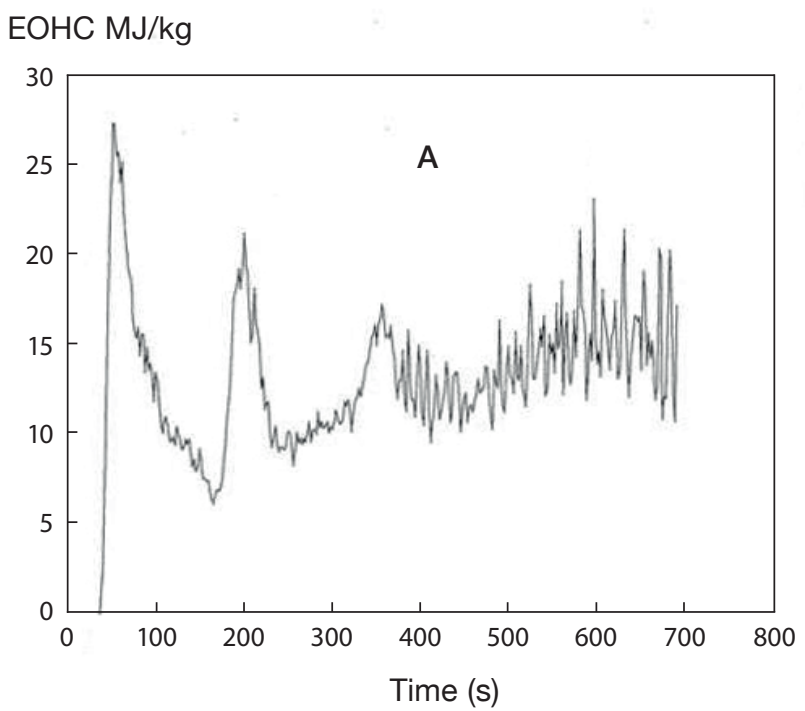

LEC $(1 / m)$

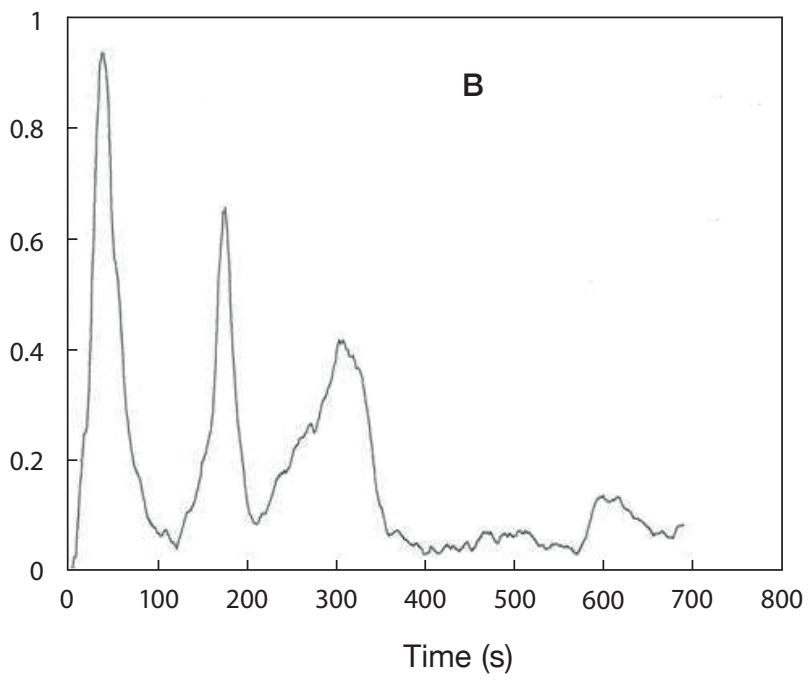

Fig. 3. Comparison of the profile of the effective heat of combustion (EOHC) (A) with the Light Extinction Coefficient (LEC) in the ventilation pipe of the cone calorimeter (B) - test results for plywood (No 3 in Table 1) at $50 \mathrm{~kW} / \mathrm{m}^{2}[26]$ 
observed correlation proves that there is a dependency between the sample degassing or smoke formation (LEC) and combustion expressed in this case by the effective heat of combustion (EHOC). Additionally, Figure 3A shows an oscillating growth of the effective heat of combustion resulting from the flameless combustion (smouldering) following the self extinguishing of the flame within $400 \mathrm{~s}$ from the beginning of the test. This is an effect typical for cellulose products that also have different profiles of heat release rates, the clearly visible second peak typical for flameless combustion (smouldering) in solid phase (Fig. 4a) [27].

a)

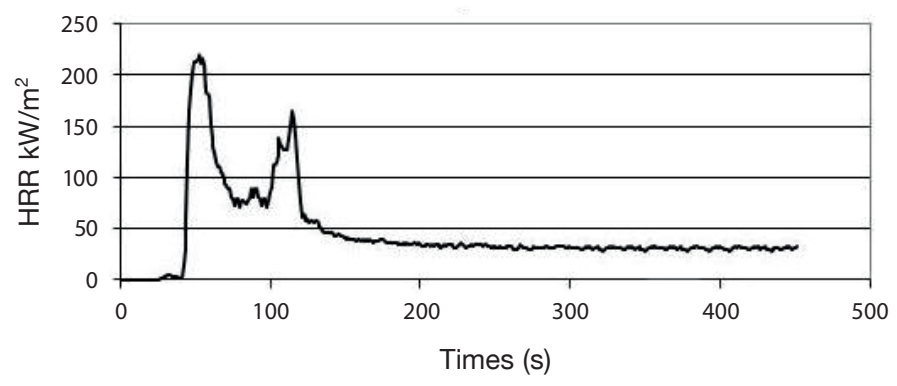

b)

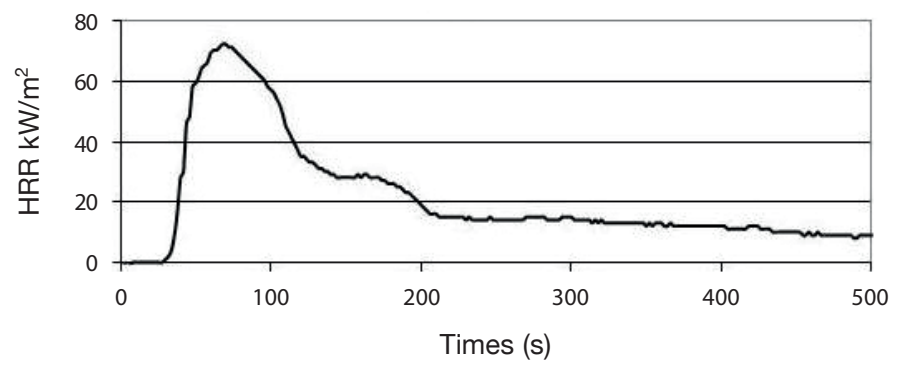

Fig. 4. Typical profiles of heat release rate (HRR) obtained in a cone calorimeter: a) plywood b) gypsum board [27]

2.2. Fire/flame spread. The process of flame spread may be considered as a progressive front of ignition, where the leading edge of the flame acts as a heat source to heat the fuel before the flame front, until the point of ignition [4-6, $8,28]$. The location of the surface and direction of the flame propagation have a significant impact on the rate of flame propagation. The change of physical reactions between flame and unburnt fuel, as for the orientation, i.e. the change of the angle of inclination, significantly influences the growth of the flame propagation rate. Due to heat transfer by way of convection, flame propagation is faster for vertical-up burning. The ability of flame/fire propagation in a room is determined by the measurement of the total heat flux (HRR, kW) conducted with the use of a heat flux meter placed in the geometrical centre of the floor in a standardised test room with a small cubic volume [18], designed especially for this purpose. The measurement also covers the effect of the source of ignition,

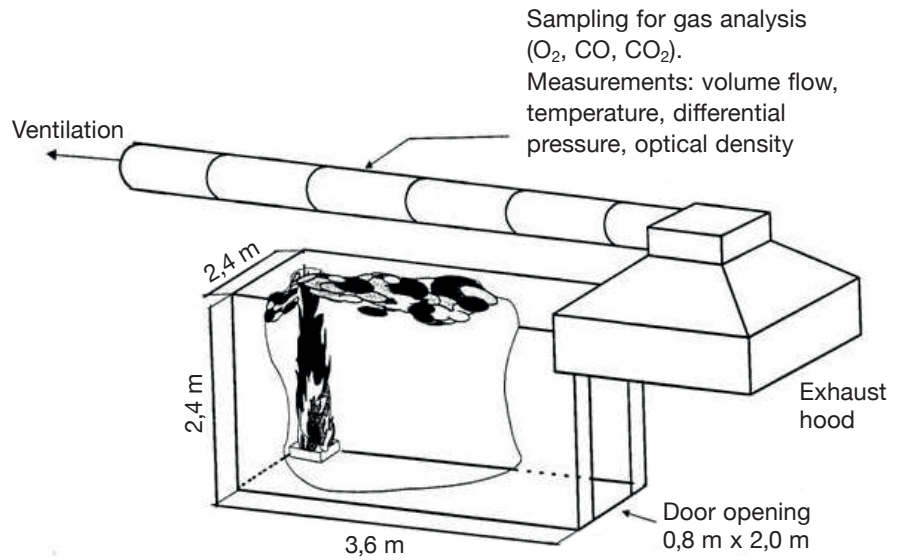

Fig. 5. Scheme of room corner test set up according to $[18,27]$

i.e. the flame of the so-called sand burner supplied with propane. The upper surface of the $0.31 \mathrm{~m} \times 0.31 \mathrm{~m}$ burner, made of flame-resistant material, is located $0.3 \mathrm{~m}$ above the floor in the corner of a room (Fig. 5). Immediately after ignition, the fire in a room develops freely, as in an open space. A change of the fire scale occurs either as a result of the spread of flame within the first ignited element or thing (object), or as a result of the transfer of flame to other neighbouring elements or things (objects).

2.3. Flashover. Theoretical variations for the average temperature of gases or total heat flux over time in a relatively small room (Fig. 5) are referred to in the literature as a fire curve (Fig. 6). Not many fires proceed according to this curve, but it is useful when it comes to explaining the nature of fire development and analysing the fire phases [4, 7, 14, 15, 17, 29, 30]. After the first initial phase, characterised by a slow increase of temperature and the total flux of heat, a fire may either spontaneously self-extinguish, due to lack of fresh fuel necessary to

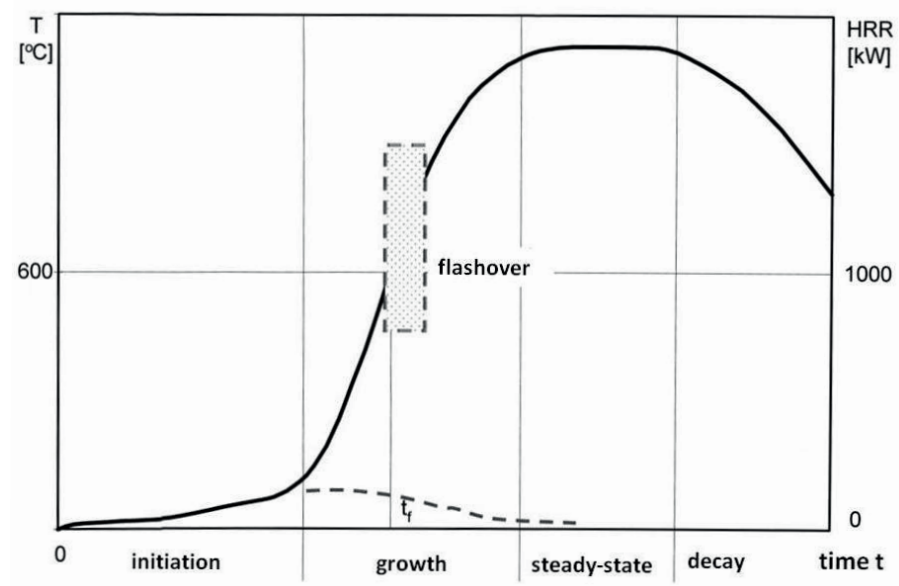

Fig. 6. Phases of room fire [21] 
sustain the reaction of combustion (this situation is illustrated by the dashed curve) or develop further and go into the growth phase. In certain conditions, i.e. ones that are favourable for the development of fire, an event may occur involving the sudden burning of the entire surface of combustible material within a separated space, which is referred to as a flashover. This event divides the process of fire development into two major and different (in terms of their nature) phases which are of significance for the fire safety of buildings - before and after flashover. The phase before flashover is characterised by relatively inconsiderable thermal effects of fire on the structure. In this phase, a fire may easily be restricted to the room in which it was initiated, preventing its further propagation.

The flashover is followed by the full development of fire, including a steady-state phase, during which both the total heat flux and the average temperature of the gases in a room reach the maximum values and basically do not change. In the phase after flashover, a fire may easily spread to other or adjacent rooms, or even rooms which are far away from the place where the fire initially ignited, e.g. the fire may spread through ventilation ducts to rooms which are very distant inside the building.

a)

$\mathrm{HRR}(\mathrm{kW})$

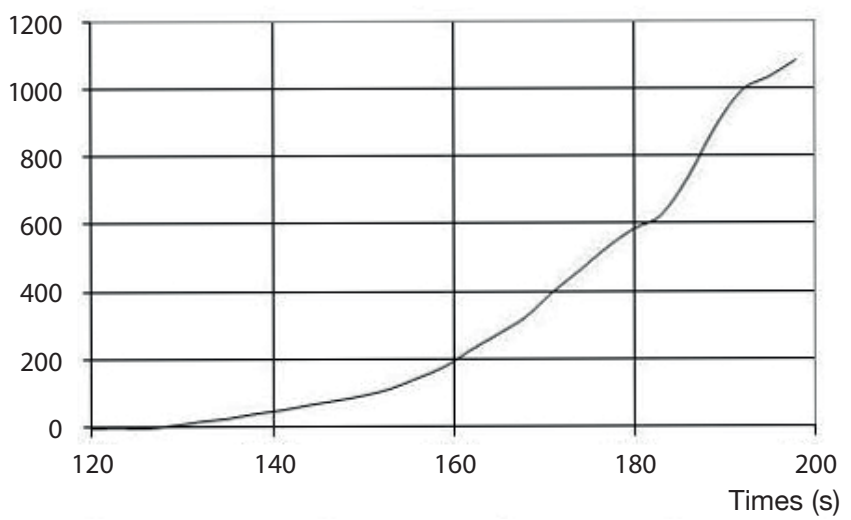

b)

HRR (kW)

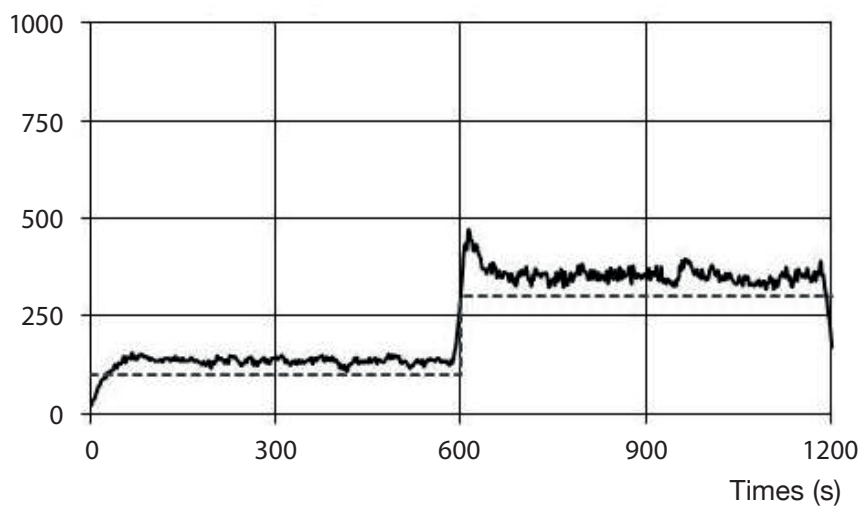

Fig. 7. Typical profiles of the total heat release rate in the Room Corner test [21]: a) PVC lining fixed to the walls of a room with the use of adhesive b) gypsum board with three coats of acrylic paint
After the flashover, the fire is also likely to be transferred to structures adjacent to the building. When a reaction of combustion covers a relatively large area of the combustible material, the oxidiser (oxygen from the air) is exhausted and the process of combustion slows down, because it is controlled by the availability of the oxidiser. At the final phase, after combustion and then cooling to room temperature occur, the temperature and the heat flux decrease. In a series of tests on fire development in a test room of ITB laboratory in Warsaw for a group of 11 surface products [27], including for example: plywood, gypsum board, gypsum fibreboard (cellulose fibre), silicate board, two characteristic profiles of the total heat flux exist have been distinguished (Fig. 7).

The curve in Figure 7a represents a very fast process of fire development in which the value of $1000 \mathrm{~kW}$ - corresponding to the conditions of transfer to flashover - was reached in approx. 3 minutes. The test was interrupted for safety reasons, long before the standard time of the test that equals to 20 minutes. A different situation is shown in the curve in Fig. 7b), where the solid line illustrates the total heat flux in 20 minutes of the test and the dashed line - a profile of the total flux of heat released by a propane (sand) burner with a special design, used in this test as a standard source of ignition.

We may observe a step increase of thermal power of the burner by $100 \mathrm{~kW}$ during the first 10 minutes from firing, up to $300 \mathrm{~kW}$ in the next 10 minutes of the test. The increase of the total heat flux above the burner flux from the material is insignificant (max. $120.51 \mathrm{~kW}$ ) and short-term (decrease to the value below $100 \mathrm{~kW}$ in $60 \mathrm{~s}$ ). The plot shown in Fig. 7a) is characteristic for a combustible product, whereas the one in Fig. $7 b$ ) for a non-combustible product.

\section{Building performance of products and fire safety}

Fire may burn with or without flames (smouldering or glowing). Flameless combustion results from the deficiency of oxidiser in the reaction zone [31-34]. This situation is frequently observed in the conditions of real fire, particularly in the decay phase. Sometimes flameless combustion may occur in buildings without being noticed for a long time (several days), creating a fire hazard - this applies particularly to insulation made of sandwich panels [34]. Combustible products become fuel during the fire. Fire causes their thermal and chemical degradation. Even non-combustible materials may pose a threat to the evacuees and rescue teams due to the loss of their properties, which affects the fire safety of a building (e.g. high-strength concrete, steel). Addition of retardants may have a short-term effects in the fire conditions and cause environmental and health problems for people evacuated from the building. It is an issue which is often omitted or downplayed in a general fire safety strategy.

Transition from smouldering to flaming combustion is a critical point in fire development. The long term flameless combustion regards mainly combustible insulation products of small density and large porosity. The additional amount of 
oxidizer is located inside pores and supports the sustained combustion and its propagation. Fire is a source of convective flows inside building due to the formed temperature gradients. Transition from smouldering to flaming combustion strongly depends on flow over the combustible surface. The minimum velocity of $2 \mathrm{~m} / \mathrm{s}$ is necessary to undergo transition to flaming in case of forward smouldering under increased forced flow. Opposed smouldering propagation do not occurs at flow velocities below $5 \mathrm{~m} / \mathrm{s}$ [32]. Even non-combustible products may cause a danger in fire situation. Even if a given material does not burn in a fire it does not necessarily preserves its chemical and physical properties. Usually, the following observations are made: the loss of strength, appearance of flaws and cracks, dripping and falling of combustion residues as a result, initially water evaporation and then gasification. In the case of load-bearing construction elements, even those made of non-combustibles, there occurs the possibility of loss of resistance, dangerous for the whole construction, evacuation of habitants and firemen action [35]. Problems related to building products are not sufficiently addressed in fire safety research and strategy. Current approach of "global parameters" do not increase knowledge in this field and it is now and it will be the barrier in future development of new products and their application in construction. It becomes necessary to better connect the results of tests with the real processes which undergo in products during fire. The example of it is a presented concept of modified heat of combustion (Section 4).

Technical aspects of the fire safety of buildings linked to combustion vary depending on the phase of fire. One may distinguish the following [35]:

1) in the phase before flashover:

- providing evacuation of people and protection against injuries

- limitation of the initial flame effects

- reducing the rate of fire development in place of its generation

- limiting the possibility of fire transfer to other rooms of a building

2) in the phase after flashover:

- considering safety of rescue team

- safe evacuation of people from buildings

- limiting the fire transfer to other separated zones of the building, including the so-called safe zones

- transfer of fire to adjacent objects

- protection of property and maintenance of the building function.

The problems addressed in this study are connected to the issues underlined below. One of the most important fire safety problems is to differentiate between combustible and non-combustible products. For example in European system [36, 37] the methods and criteria which are currently used allow to put the products in the raw and to compare than on the basis of arbitrary define criteria values for the defined classification groups. This criteria are not based on the fire development process, for instance flashover can undergo at the average temperature range between $300^{\circ} \mathrm{C}$ to $600^{\circ} \mathrm{C}[29,30]$, while the non-combustibility test [38] is performed in the temperature of $750^{\circ} \mathrm{C}$. Within the range of temperatures corresponding to the phases of flashover and after the flashover the time until auto ignition, and temperature increase by $20^{\circ} \mathrm{C}$ (difference of value $\Delta \mathrm{T}$ for currently used classes A1 and A2) are not significant.

\section{Concept of modified heat of combustion and its verification}

Certain problems of $\mathrm{HC}$ data direct use for building materials in real fire analysis are reported, for instance in $[39,40]$. One of the most common problems occurs for charring materials, for which the heat of combustion of volatiles is not equal to that of the whole material. To omit these problems, I proposed to use the solution as follows [11]:

$$
\mathrm{MHC}=\mathrm{HC} \times \Delta \mathrm{m}[\mathrm{MJ} / \mathrm{kg}]
$$

where:

$\mathrm{MHC}$ - modified heat of combustion $[\mathrm{MJ} / \mathrm{kg}]$

$\mathrm{HC}$ - gross heat of combustion $[\mathrm{MJ} / \mathrm{kg}]$ according to EN ISO 1716 [41]

$\Delta \mathrm{m}$ - sample mass loss [-] according to EN ISO 1182 [38]

The MHC concept uses measurements from both above mentioned methods and increase the possibility to better identify non-combustible (class A1) and combustible products (the remaining classes). This concept was verified on the basis of analysis of test results for 66 commercial building products, which were grouped into five categories, depending on their intended use in the building:

I. Concrete and ceramic

II. Thermal/acoustic insulations

III. Covering boards (wall/ceiling)

IV. Mortars and adhesives

V. Thin coatings

The heat of combustion (HC) data (Fig. 8) presented a very wide range; for products under endothermic chemical reactions $\mathrm{HC}$ values below zero were found for 18 of 66 samples, mostly in the group of mortars and adhesives.

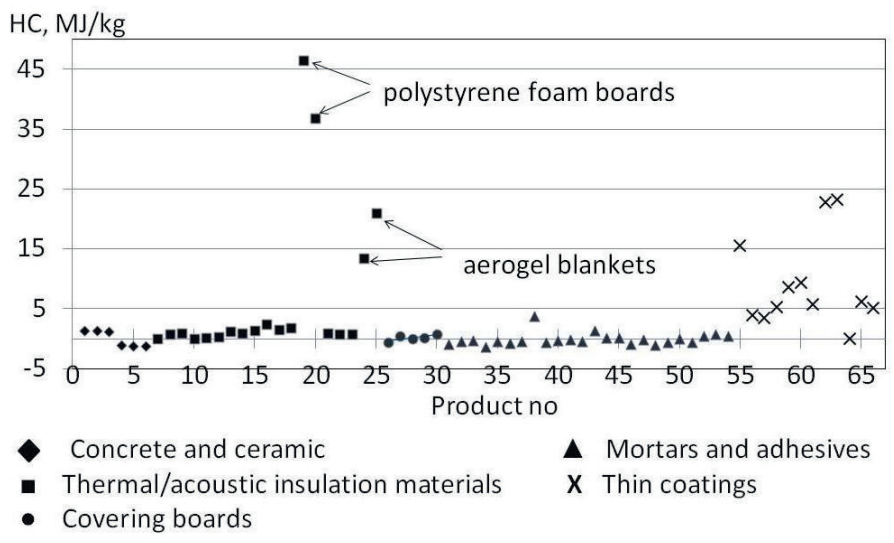

Fig. 8. Results for heat of combustion for 66 commercial building products; based on [11] 

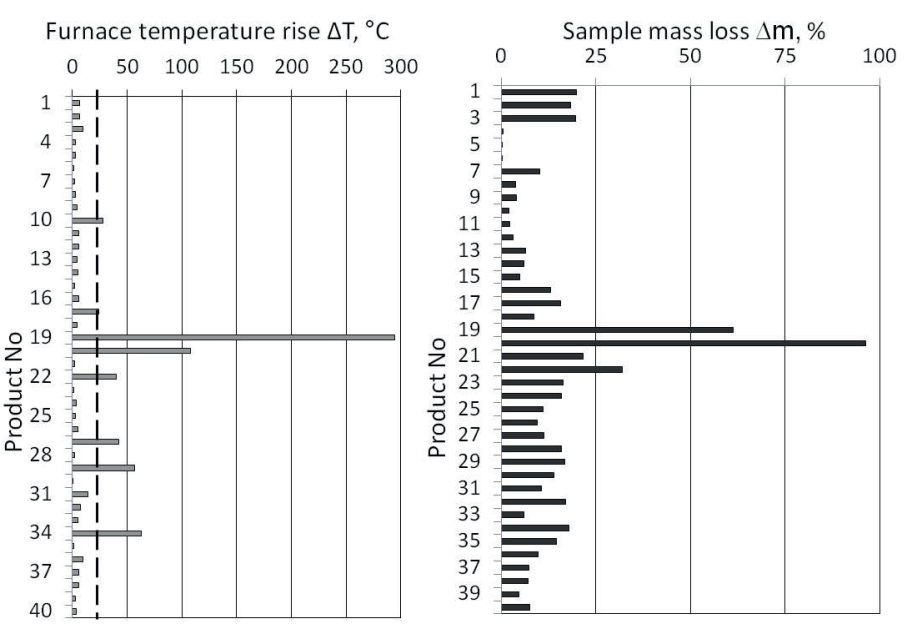

Fig. 9. Comparison of non-combustibity test results by method [38, 11]. Class A1 criteria: $\Delta \mathrm{T} \leq 30^{\circ} \mathrm{C}$ (dashed line), and $\Delta \mathrm{m} \leq 50 \%$ [36]

The highest $\mathrm{HC}$ values were found equal to $46,49 \mathrm{MJ} / \mathrm{kg}$ in case of regular polystyrene foam, while for fire retarded polystyrene foam this value was less and equal to $36.84 \mathrm{MJ} / \mathrm{kg}$. These level of HC is even higher than reported for real industrial coals of which $\mathrm{HC}$ values were found between $7.5 \mathrm{MJ} / \mathrm{kg}$ (low rank brown coal [42]) and $28 \mathrm{MJ} / \mathrm{kg}$ (anthracite coal [43]). For wood average HC may be found as high as $18.5 \mathrm{MJ} / \mathrm{kg}$ [20]. More details on this study are available in my work [11].

On the basis of experimentally obtained $\mathrm{HC}$ and $\Delta \mathrm{m}$ values, the MHC was calculated using formula (1) (Fig. 10).

Futhermore, results are presented graphically and compared with the class $\mathrm{A} 1$ criteria for $\Delta \mathrm{T}$ and $\Delta \mathrm{m}$ as a function of $\mathrm{HC}$ (Figs. 11, 12). The horizontal and vertical axes cross at the limit points for the criteria values of $\Delta \mathrm{T}$ and $\mathrm{HC}$ (Fig. 11) or $\Delta \mathrm{m}$ and HC (Fig. 12) according to [36]. Four areas can be distinguished

\section{$\mathrm{HC}, \mathrm{MHC}, \mathrm{MJ} / \mathrm{kg}$}

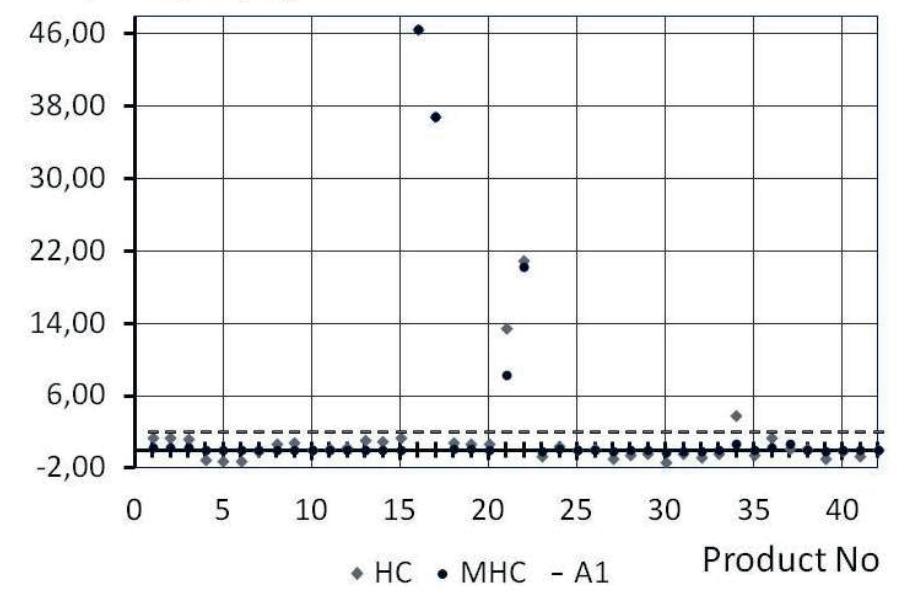

Fig. 10. Comparison of HC measured in oxygen bomb calorimeter [41] with the calculated modified heat of combustion - MHC and with the criterion for Euroclass A1 (dashed line)

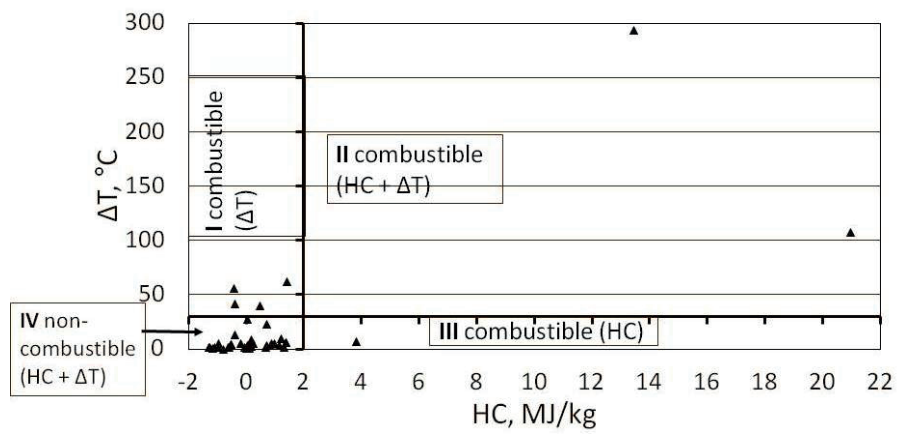

Fig. 11. Comparison of results with the criteria for Euroclass A1[36]: $\Delta \mathrm{T} \leq 30^{\circ} \mathrm{C}$, and $\mathrm{HC} \leq 2 \mathrm{MJ} / \mathrm{kg}$

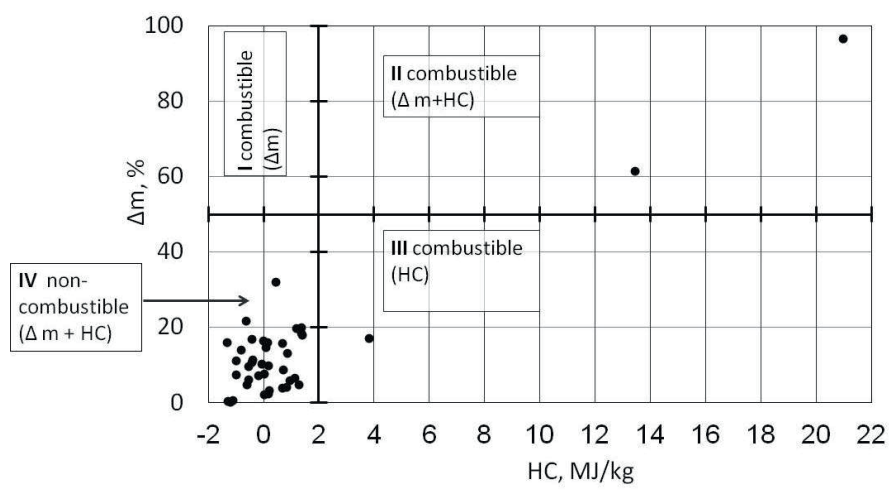

Fig. 12. Comparison of results with the criteria for Euroclass A1 [36]: $\Delta \mathrm{m} \leq 50 \%$, and $\mathrm{HC} \leq 2 \mathrm{MJ} / \mathrm{kg}$

in each of these figures. The points located to the left of the vertical axis present accordance with the A1 criterion $(\mathrm{HC} \leq 2$ $\mathrm{MJ} / \mathrm{kg}$ in both figures. With the only four exceptions in case of $\Delta \mathrm{T}$ (see Fig. 11) and no exceptions for $\Delta \mathrm{m}$ (Fig. 12), consistence of the A1 classification is almost perfect.

In conclusion, EN 1716 method [37] is very convenient and reliable tool for time and cost-effective evaluation of building products in the range of non-combustibility. On the basis of the single $\mathrm{HC}$ value one can predict the fire evaluation particularly to differentiate non-combustibles and combustibles within building products. It would be essential for the future design and implementation of new products in the construction industry.

\section{Summary}

In the course of this study, a new research area was identified within building fire safety, which is essential due to the increasing significance of future environmental requirements. An original approach to the research and analysis aimed at explaining the physical phenomena occurring in construction products in the initial phase of fire development, consequently affecting the level of fire safety in buildings. The examples are systematic studies of ignition surface temperature of wood based products. The major findings are as follows: 
- Development of modified heat of combustion concept as a single quantity, which combines the results of both current test methods. The modified heat of combustion is more suitable for characterizing the fire properties of building products than the gross heat of combustion.

- The testing of gross heat of combustion is a very effective way of preliminary determination related to the fire properties of products; especially those with combustible organic additives. EN ISO 1716 is very convenient and reliable method for time and cost-effective evaluation of building products in the range of combustibility. On the basis of the single $\mathrm{HC}$ value it is possible to predict the fire evaluation particularly to differentiate non-combustible and combustible building products. It would be essential for the future design and implementation of new products in the construction industry. However, one should bear in mind, that the third criterion of auto ignition in the second non-combustibility test EN ISO 1182 could influence the final A1 classification of the building product. The relatively simple and low-cost measurement of gross heat of combustion is proposed for all Euroclasses of building products with different limit values.

- Having such a suitable method, for the purposes of a preliminary assessment of the combustible products with high accuracy, will be important at the stage of design and implementation of new products in the construction industry.

- There are six major criteria for building product evaluation, resulting from the combustion processes that occur during a fire: (1) heat of combustion, (2) temperature rise, (3) mass loss, (4) heat release rate, (5) flame/fire propagation rate, (6) smoke generation.

- Each of the evaluation criteria may be assigned with limited values, resulting from the analysis of the product combustion process, which will enable verification of the requirements. An example is the concept of the modified heat of combustion presented herein, combining the results of two tests in a single quantity.

Further studies should focus on the connection between the results of the experimental tests concerning reaction to fire and the calculations. This will gradually be possible as new products emerge.

\section{REFERENCES}

[1] www.kgsp.pl, (2015), [in Polish].

[2] R. Mazur, "Statistic analysis of fires in Poland", in: Red Book of Fires. Part II. Fire Statistics, CNBOP, Józefów, 2014, [in Polish].

[3] J.L. Torero, "Scaling-up fire", Proc. Comb. Inst. 34, 99-124 (2013).

[4] D. Drysdale, Introduction to Fire Dynamics, John Wiley and Sons Ltd., 1985.

[5] C. Fernandez-Pello, "The solid phase", in: Combustion fundamentals of fire, pp. 55-85, ed. G. Cox, Academic Press, 1995.

[6] Y. Hasemi, "Surface flame spread", in The SFPE Handbook of Fire Protection Engineering, 4th ed., pp. 2-278-2-290, NFPA, 2008.

[7] A.P. Mouritz and A.G. Gibson, Fire Properties of Polymer Composite Materials, Springer, 2006.
[8] J. Fangrat, "Study on process of flame spread over solid polymeric layer", PhD Thesis, Fac. Power and Aer. Eng., Warsaw University of Technology, Warsaw, 1989, [in Polish].

[9] J. Fangrat, P. Wolański, "Major factors influencing flame spreading over solid fuel layer" in: Dynamics of deflagrations and reactive systems: Heterogeneous combustion, American Institute of Aeronautics and Astronautics, Washington, USA, 261-274 (1991).

[10] J. Fangrat, "Effect of increased organic content on fire properties of building products", Building Materials 12, 35-40, (2012), [in Polish].

[11] J. Fangrat, "On non-combustibility of commercial building materials", Fire and Materials, doi:10.1002/fam.2369 (2016).

[12] L. Czarnecki, M.P. Kaźmierkowski, and A. Rogalski, "Doing Hirsch proud: Shaping H-index in engineering sciences", Bull. Pol. Ac.: Tech. 61 (1), 5-22 (2013).

[13] L. Czarnecki and J.J. Sokołowska "Material model and revealing the truth", Bull. Pol. Ac.: Tech. 63 (1), 7-14 (2015).

[14] V. Babrauskas and R.B. Williamson, "Post-flashover compartment fires", Rept. No. UCB FRG 75-1, Univ. Calif., Berkeley, 1975.

[15] A.H. Buchanan, Structural Design for Fire Safety, John Wiley \& Sons Ltd., Chichester, UK, 2002.

[16] J. Fangrat, "Effect of increased organic content on fire properties of building products", Building Materials 12, 35-40 (2012), [in Polish].

[17] M. Abramowicz and R.G. Adamski, Building Fire Safety, SGSP, Warsaw, 2002, [in Polish].

[18] ISO 9705:199,3 "Fire tests - Full-scale room test for surface products".

[19] ISO 5657:1986, "Fire tests - Reaction to fire - Ignitability of building products".

[20] V. Babrauskas, Ignition Handbook, Fire Science Publishers, 2003.

[21] J. Fangrat, "Discussion on criteria proposed for ISO ignitability test", Arch. Combustionis 12 (1-4), 185-196 (1992).

[22] ISO 5660:1990, "Fire tests - Reaction to fire - Rate of heat release from building products".

[23] J. Fangrat, Y. Hasemi, M. Yoshida, and T. Hirata, "Surface temperature at ignition of wooden based slabs", Fire Safety Journal 27 (3), 249-259 (1996), erratum: Fire Safety Journal 28 (4), 379-380 (1997).

[24] M.L. Janssens, Heat Release in Fires, pp. 267-270, eds. V. Babrauskas and S.J. Grayson, Elsevier Applied Science, London, 1991.

[25] Q. Jianmin, Heat Release in Fires, pp. 293-306, eds. V. Babrauskas and S.J. Grayson, Elsevier Applied Science, London, 1991.

[26] J. Fangrat, Y. Hasemi, M. Yoshida, and S. Kikuchi, "Relationship between heat of combustion, lignin content and burning weight loss", Fire and Materials 22 (1), 1-6 (1998).

[27] J. Fangrat, "Experimental and theoretical evaluation of time to flashover in a room fire scenario", Arch. Combustionis 23 (1-2), 31-45 (2003).

[28] J. Fangrat and P. Wolański, "One-dimensional analytical model of flame spread over solids", J. Fire Sc. 9 (5), 424-437 (1991).

[29] W.D. Walton and P.H. Thomas, "Estimating temperatures in compartment fires", in The SFPE Handbook of Fire Protection Engineering, 4th ed., p. 3-204, NFPA, 2008.

[30] P.H. Thomas, "Testing products and materials for their contribution to flashover in rooms", Fire and Materials 5 (3), 103-111 (1981). 
[31] J. Fangrat, "Is flameless combustion of importance to fire safety?", Arch. Combustionis 24 (1), 1-4 (2004).

[32] T.J. Ohlemiller, "Smouldering combustion propagation through permeable horizontal fuel layer”, Comb. Flame 81, 341-354 (1990).

[33] J. Buckmaster and D. Lozinski, "An elementary discussion on forward smoldering", Comb. Flame 104, 300-310 (1996).

[34] T.J. Ohlemiller, "Smouldering combustion", in The SFPE Handbook of Fire Protection Engineering, 4th ed., pp. 2-229-2-259, NFPA, 2008.

[35] J. Fangrat, "How much fire safety in building products?", Building Materials 11, 36-39 (2014), [ in Polish].

[36] EN 13501-1, "Fire classification of construction products and building elements - Part 1: Classificatin using test data from reaction to fire tests".

[37] J. Fangrat, "European classification of building products and elements", Building Materials 3, 44-48 (2004), [in Polish].
[38] EN ISO 1182, "Reaction to fire of building materials - Non combustibility test".

[39] M. Dietenberger, "Update for combustion properties of wood components", Fire and Materials 26, 255-260 (2002).

[40] J. Madrigal, M. Guijarro, C. Hernando, C. Diez, and E. Marino, "Effective heat of combustion for flaming combustion of Mediterranean forest fuels", Fire Technology 47, 461-474 (2011).

[41] EN ISO 1716, "Reaction to fire of building materials - Determination of gross calorific value".

[42] H. Pawlak-Kruczek, "Co-firing of biomass with pulverised coal in oxygen enriched atmosphere", Chemical and Process Engineering 34 (2), 215-226 (2013).

[43] H. Pawlak-Kruczek, "Problems of the combustion of young low-metamorphism rank fossil fuels", Wrocław University of Technology, Wrocław, 2003, [in Polish]. 